Copyright. Citation Information: Vaniya, N., Noran, O., Bernus, P. (2014). Merger and Acquisition Preparedness Building: An Enterprise Architecture Perspective. In Improving Enterprise Communication (Proceedings of the 22nd International Conference on Information Systems Development), M. José Escalona, et al. (Eds.), Springer Verlag: pp. 171-183..

\title{
Merger and Acquisition Preparedness Building: An Enterprise Architecture Perspective
}

\author{
Nilesh Vaniya, Ovidiu Noran and Peter Bernus \\ Griffith University Australia, School of ICT, \{n.vaniya, o.noran, p.bernus\}@griffith.edu.au
}

\begin{abstract}
The increasing rate of Mergers and Acquisitions (M\&As) draws attention of researchers and academics alike; however, the significant failure rate of such complex enterprise-wide transformations typically posing 'wicked' problems suggests a significant potential for improvements. Much research has been conducted to investigate the issues and problems in M\&As in order to find and propose various ways to increase the percentage of positive outcomes. This abundance of M\&A research creates a need to synthesise the existing results in order to propose a collective way to address M\&A issues. In addition, due to the complexity, dynamicity and time constraints of M\&As it seems that there is little time to implement the recommendation of the research community. This paper proposes a way to address this dilemma through building preparedness for M\&As. Thus, before the actual M\&A implementation, organisations undertake preventative measures to acquire necessary systemic properties (such as flexibility, agility, etc.), in order to be in a better position to address anticipatable or emergent issues.
\end{abstract}

\section{Introduction}

Mergers and Acquisitions (M\&As) are practiced in order to achieve a variety of business goals and objectives. This complex and dynamic practice serves a range of stated purposes, such as economies of scale, resource acquisition or market sharing, and governance-related uses such as the restructuring of the banking industry. M\&As typically pose complex and 'wicked' [29] problems, where solving one aspect in isolation may upset other areas and 'good', rather than 'perfect' solutions exist. This suggests the use of a holistic approach considering all relevant aspects of the M\&A project at hand in an integrated rather than isolated manner.

This paper aims to tackle this problem by presenting the principles and use of a 'Mergers and Acquisitions Preparedness Building' (MAPB) approach built on Enterprise Architecture (EA) concepts in order to create and support strategically important transformational activities, in a whole-system life cycle-based manner. The proposed MAPB approach comprises an 'M\&A Issues Identification and Categorisation (MAIIC) Model, as well as an M\&A Preparedness Building Methodology (MAPBM). We start by describing the proposed MAPBM which aims to 
support enterprises in acquiring the necessary systemic properties before merger/acquisition and thus build preparedness for one or more desirable types of M\&A, which management considers as future strategic options. Subsequently, we describe a merger case study and using the MAPBM we demonstrate how, with strategic intent, a multifaceted transformation of the participating organisations could have been performed so as to achieve a state of organisational readiness to perform a strategically attractive merger.

\section{Mergers and Acquisitions: Problems and Solutions}

Mergers and Acquisitions can be of different types, such as Horizontal, Vertical, Conglomerate [13] or Forced and Voluntary [12, pg. 26-27]. Irrespective of the type, M\&As can deliver positive outcomes; Walter [25, pg. 62-77] lists some advantages such as market extension, economies of scale, cost (or revenue) economies of scope and other operating efficiencies.

Current research $[3,16,19]$ suggest that while the rate of M\&As has increased, the probability of achieving the above mentioned potential benefits has dropped to less than $50 \%$. In the following discussion we categorise major M\&A issues that cause such high failure rate.

The major M\&A issues can be grouped into three key categories: 1) Business Management 2) Human Resource (HR) and 3) Information Technology (IT) and Information Systems (IS). These three categories of issues may have interrelationships or interdependencies; for example, as demonstrated by Robbins and Stylianou [21] as well as Baro, Chakrabarti and Deek [5] the success of Post-merger system integration relies on IS and Organisational factors. To consider such interrelationships a so-called 'systems approach' [17, pg. 4; 14; 6] would provide a unified framework able to represent the range of problems that arise from the transformation of two systems into a single system. The next questions would be a) can all issues be addressed in detail before M\&A in all circumstances? b) if not, then what kind of issues can be addressed? c) at what level of detail? and d) how to identify those issues? This research is set to identify which type of issues can be addressed, by whom, when and how.

The key requirements for a harmonised solution are discussed in the literature. Examples of such requirements are: maintain business-IS alignment during Postmerger Integration (PMI) [26], consider the level of integration required [24], configure a clear Information and Communication Technology (ICT) vision [14], careful integration planning of IS components such as enterprise applications and platforms (operating systems, communication, security, and database systems) [4]. For PMI, various approaches have been suggested for all three categories of issues. For IS PMI, Giacomazzi, Panella, Pernici and Sansoi [9] suggest a model to list available options (Total Integration, Partial Integration, No Integration and Transition) for given computer and software architectures. For PMI of application systems, recent attention was drawn to the role and utilisation of ERP systems in 
M\&As [e.g., 10, 11], resulting in a methodology to develop an Application Integration Strategy [7, 18]. To address HR PMI issues, Schuler and Jackson [22] suggest a three-stage HR integration model (pre-combination, combination and solidification). Their model covers major HR activities, strategies and planning for successful HR PMI. To explain the PMI process, Mo and Nemes [17] suggest developing the metaphor of an architectural 'DNA' (biological DNA) inheritance. Thus, using a 'DNA EA' concept, they explain post-merger integration as the inheritance of processes, knowledge, control, data, people and assets of the involved organisations into the DNAs of the merged organisation.

During PMI it will be necessary to design an agile and quick responsive operating model which can be tailored to the organisation's needs. Ross, Weill and Robertson [20] suggest that the level of business process integration (sharing data across parts of the organisation and thus requiring business data integration) and the level of business process standardisation (use of uniform business processes across the organisation) can decide an operating model for the organisation.

In summary, although the outlined solutions are able to address individual categories of issues, it is necessary to consider the impact of such solutions in the context of other types of issues. In our view, a systems approach is needed to synthesise the proposed solutions into a workable and comprehensive methodology.

\section{An M\&A Preparedness Building Approach}

As demonstrated in [1], a potential solution to address the above-mentioned concerns is M\&A preparedness building. Figure 1 shows the conceptual layout of the proposed MAPB solution.

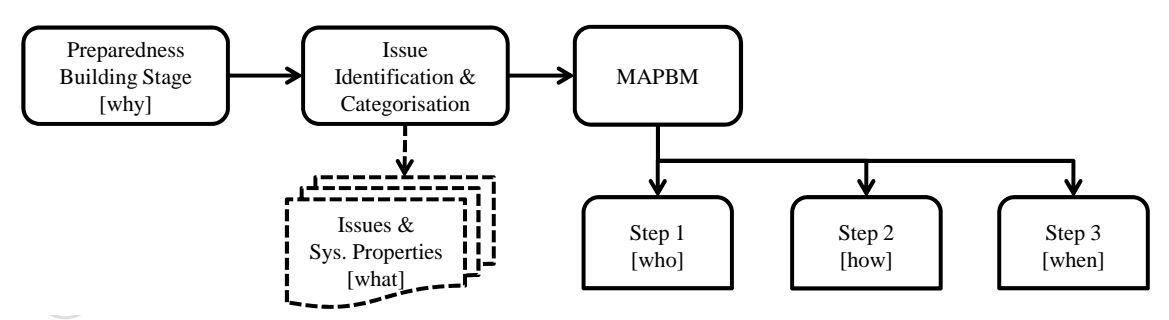

Fig.1 Proposed M\&A Preparedness Building Approach

Using the conceptual blocks of MAPB approach highlighted in Fig.1, we have previously investigated the why, who, how and when of M\&A preparedness building [1,2]. However, one question remains: how to identify the M\&A preparedness building activities? To answer it, in this paper we propose a way to identify and categorise M\&A issues that can occur in PMI and demonstrate how to use these issues to identify the preparedness building activities. 


\subsection{Identification and Categorisation of M\&A issues (MAIIC)}

One of the goals of preparedness building is to gain the ability to make informed decisions in time during the merger process. A possible way to achieve such ability is by gaining a comprehensive understanding of the situation at hand (i.e., the merger process and potential issues that the organisation might encounter during the process). To understand the issues and to identify their possible alternatives solutions, we need to consider two aspects of the issues: the ability to control and the ability to anticipate the issues.

Stylianou, Jeffries and Robbins [23] categorise post-merger IS integration success factors as Controllable and Uncontrollable. After identifying the issues pertaining to the merger case, it is necessary to understand the nature of issues (i.e. controllable vs. uncontrollable) in order to tailor the preparedness building exercise case by case.

The other ability can be explained using commonly used terms of medical and pharmaceutical sciences, i.e. preventable and curable. There is a clear difference between these two categories that is the ability to anticipate the disease decides the possible treatments and their timings.

Based on these two abilities of an enterprise any transformational issue can fall into one of the categories shown in Fig. 2. This categorisation can:

- $\quad$ support the planning of potential tasks for a preparedness building exercise,

- $\quad$ help determine the objective during the Post-Merger Integration (PMI),

- $\quad$ support management to make informed decisions about possible courses of action in case of occurrences of any anticipated or emergent issues.

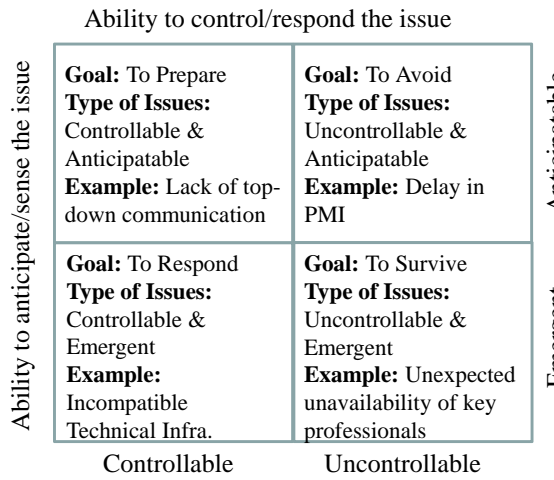

Fig.2 A model to identify and categorise M\&A Issues (MAIIC Model)

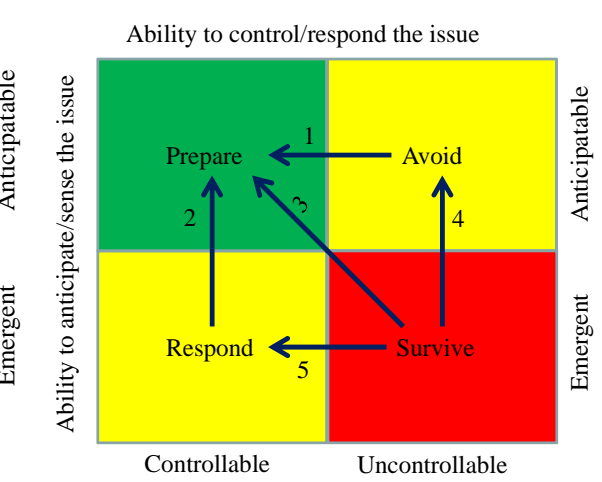

Fig.3 Potential tasks of MAPBM

As demonstrated in Figure 3, any issue can be categorised as: (a) Controllable \& Anticipatable, (b) Uncontrollable \& Anticipatable, (c) Controllable \& Emergent or 
(d) Uncontrollable \& Emergent. As a consequence, for effective and efficient PMI, organisations should be prepared for all type (a) issues, should avoid type (b) issues, should effectively respond to the type (c) issues, and should survive the effects of type (d) issues. Potential tasks of a preparedness building exercise:

- $\quad$ prepare for all type (a) issues

- $\quad$ convert all the other types of issues into type (a) issues (Arrows 1 to 5, Fig.3) and do the above, or

- if the above cannot be achieved then acquire relevant systemic properties and/or architectural design so that the enterprise can meet the respective goals based on the type of issues.

However, as reported in literature [15], not everything can be planned for at micro level in such dynamic and complex change events as M\&A. Therefore, during a preparedness building exercise,

- Type (d) issues can be responded if their controllable factors can be identified (Path 5), or

- $\quad$ Type (d) issues can be avoided if they could be anticipated (Path 4), or

- $\quad$ Type (d) issues can be prepared for if both of the above can be done (Path 3)

- Type (c) issues can be prepared for if they could be anticipated (Path 2)

- $\quad$ Type (b) issues can be prepared for if their controllable factors can be identified (Path 1).

\subsection{The M\&A Preparedness Building Methodology (MAPBM)}

The proposed methodology (MAPBM) consists of three main steps (as demonstrated in detail in [2] based on the meta-methodology described in [27]):

Step 1: Identify the participating enterprise entities. They can be existing entities (for example existing Management team, business units, affected business processes, IT infrastructure, etc.) contributing to building preparedness, or can be additional entities required to build preparedness (for example Preparedness Building Strategic Program, Gap Analysis Project, Business-, HR- and IS- Preparedness Building Projects, etc., or even strategic partners).

Step 2: Show the role of each entity in the preparedness building transformation. Step 2 shows the role of each entity in the preparedness building transformation. Various graphical models can be used for this particular step; we have chosen the so-called 'dynamic business models' proposed by the IFIP-IFAC Task Force [28] showing the role of each entity in other entities' life cycle phases.

Step 3: Demonstrate the relative sequence of transformational activities, using life history diagrams (timeline). Step 3 attempts to demonstrate the relative sequence of transformation activities. This step follows the previously identified roles of each of the entities; based on those roles, we first identify activities to match entities' responsibilities and then we establish their relative sequence using so-called 'life history diagrams'. 


\section{Application to a Merger Case Study}

\subsection{Background}

Faculty F within university U contained several schools, with schools A and B having the same profile. School A is based at two campuses situated at locations L1 and L2, while school B is based at a single campus, situated at location L3. Historically, the schools have evolved in an independent manner, reflecting the local educational needs and demographics. This has led to different organisational cultures, HR and financial management approaches. For example, school B enjoyed a large international student intake providing funds that supported heavy reliance on sessional (contract) staff for teaching and wide availability of discretionary funds. In contrast, staff in school A had a larger teaching load and fewer funds available due to a smaller student intake.

Staff profile level between schools was significantly different, with school B featuring fewer senior positions. Course curriculums also evolved separately in the two schools, with similarly named courses containing notably different material.

Thus, although of the same profile, and belonging to the same F, schools A and B were confronted with a lack of consistency in their profiles, policies, services and resources. This situation caused additional costs in student administration and course / program design / maintenance, unnecessary financial losses as well as staff perceptions of unequal academic and professional standing between campuses, all of which were detrimental to the entire faculty.

Therefore, the management of $\mathrm{U}$ and $\mathrm{F}$ have mandated that the problems previously described must be resolved and have defined the goals of schools A and B becoming consistent in their products and resources strategy, eliminating internal competition for students and being subject to a unique resource management approach. As a solution, it has been proposed that the schools should merge into a single, multi-campus Merged School (MS). The unified MS management and policies would promote consistency in the strategy regarding the products delivered and the resources allocated to its campuses.

After further consultation, the Heads of the participating Schools have set an organisational goal allowing the individual campuses to retain a significant part of their internal decisional and organisational structure after the merger, with an added layer of overall governance structure. This structure was supported by the HR department as the simplest to implement and transition to.

From the point of view of Information Services, the proposed merger presented the opportunity to set the goal to unify and streamline software and hardware deployments across campuses. The business aspect of the merger goals concerned the elimination of internal competition and a unique merged school image. 


\subsection{The Results}

The Merged School Project has succeeded, albeit with some difficulties. The decisional, functional, information, resources and organisational models created during the merger have helped significantly to understand the present situation and to select an optimal future state. The use of languages easy to understand and able to manage complexity has resulted in stakeholder buy-in for the project and middlemanagement consensus on the essential aspect of the future MS.

Unfortunately however, most modelling and mappings (including the modelling of the pre-merger situation) occurred during the merger project itself rather than before; thus, there was insufficient time to achieve appropriate modelling detail. This has led to a 'devil in the detail' situation as the human resources allocated to accomplish the merger and post-merger integration tasks were unable to fully complete the new design before roll-out.

In addition to their inappropriate granularity, the available models were only partially applied. For example, an organisational model showing changes in roles and decisional framework in the transition from the present to the future states was implemented only at the top layer due to the lack of time and proper preparation. As a result, the Head of the newly formed MS had to spend significant amount of time 'putting out fires' (finding short term solutions to re-occurring product / resources imbalances). Thus, unfortunately the interventionist and turbulence issues outlined in the pre-merger (AS-IS) organisational and decisional models were not effectively addressed.

Staff consultation has taken place; however, a significant amount of feedback never translated into changes to the proposed organisational model. This has harmed trust and thereby has reduced the acceptance level of the merger project.

Importantly, the detailed process modelling was never completed and as such the implementation went ahead without detailed models and guidance, in a 'cold turkey' manner (i.e. overnight changeover) resulting in a state of confusion as to 'who does what' lasting several months and affecting staff and students.

On the positive side, the Merged School did achieve a unique image, and in time reached an increased level of integration and consistency across campuses and a more efficient resource administration.

\section{Application of the Preparedness Building Approach}

Preparedness can be built for announced and potential M\&As. In this case, the merger partners were known, therefore this is a case of preparedness building for an announced merger. Firstly we apply the described model to identify potential issues that can be addressed during preparedness building and then demonstrate how to plan activities based on the objectives identified by MAIIC. 


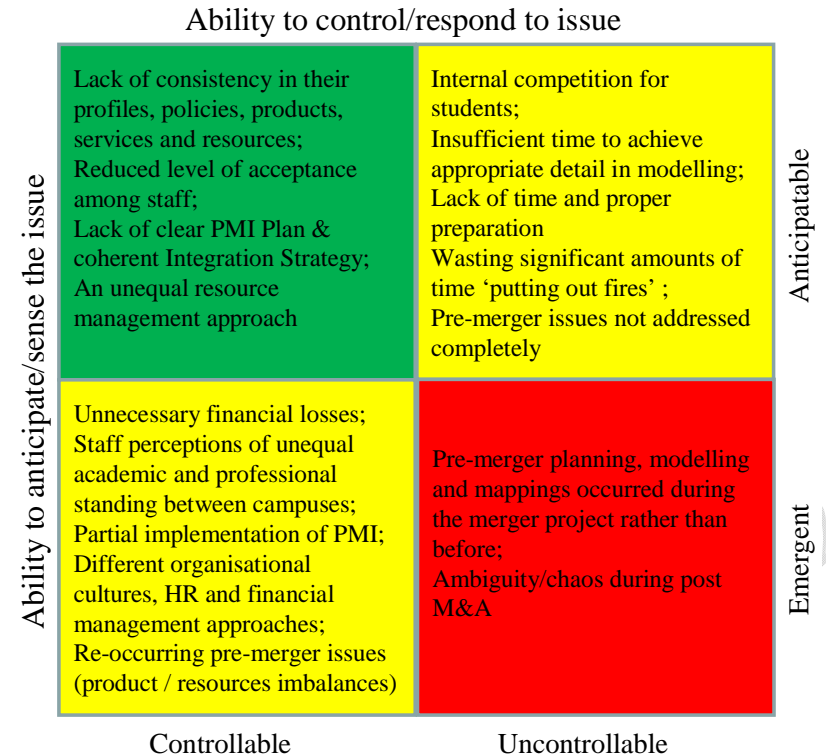

Fig.4 Identifying and categorising the merger issues in the case study

\subsection{Identifying and Categorising M\&A Issues}

From the case study, major issues in PMI can be identified and categorised as shown in Fig. 4. These issues could have been addressed for effective PMI and smooth operation of MS, however in this case the merger project failed to achieve that. As a result, there were problems after the merger and pre-merger issues reoccurred even after the merger. Also the PMI resulted in delay in realising the expected synergies and ultimately delaying the delivery of underlying values. According to Epstein [8] often such delays affect the success of M\&As.

From the above discussion, the aim of preparedness building can be set as follows:

- Identify obstacles to the transformation and implement appropriate preventive actions;

- Plan for post-merger integration based on the expected outcomes;

- Prepare a PMI Plan and an Integration Strategy;

- Involve key stakeholders (both schools' management, administration and academic staff) in the preparedness building activities

The identification of issues allows planning for detailed activities which could be implemented during preparedness building. In Table 1, based on the MAIIC, we summarise major transformational activities to build preparedness for the merger of the two schools. 


\begin{tabular}{|c|c|c|c|c|}
\hline Issue / Problem & \begin{tabular}{|l|} 
Nature \& \\
Objective
\end{tabular} & Planned Activity & $\begin{array}{l}\text { Implemen- } \\
\text { ted by }\end{array}$ & Affected Entities \\
\hline $\begin{array}{l}\text { Lack of consistency in } \\
\text { profiles, policies, products, } \\
\text { services and resources; } \\
\text { Unequal resource } \\
\text { management approach; } \\
\text { Differences in requirement } \\
\text { specification for Technical } \\
\text { Infrastructure and } \\
\text { management of IT resources }\end{array}$ & $\begin{array}{l}\text { Anticipatable } \\
\text { and Controllable; } \\
\text { Prepare }\end{array}$ & $\begin{array}{l}\text { Identify possible changes } \\
\text { into current } \\
\text { courses/programs, } \\
\text { organisational structure, } \\
\text { policies, reporting } \\
\text { mechanisms, communication } \\
\text { methods, performance and } \\
\text { resource management } \\
\text { approaches to manage and } \\
\text { maintain them in a unified } \\
\text { way }\end{array}$ & $\begin{array}{l}\text { BPBP, } \\
\text { HRPBP, } \\
\text { ISPBP, } \\
\text { Academic } \\
\text { and } \\
\text { Manageme } \\
\text { nt Staff }\end{array}$ & \begin{tabular}{|l|} 
Staff, Products \\
and Services, \\
Technical \\
Infrastructure \\
and Application \\
Services
\end{tabular} \\
\hline $\begin{array}{l}\text { Reduced level of acceptance } \\
\text { among staff; Internal } \\
\text { competition for students; }\end{array}$ & $\begin{array}{l}\text { Anticipatable } \\
\text { and } \\
\text { Controllable, } \\
\text { Prepare }\end{array}$ & $\begin{array}{l}\text { Prepare staff for the merger; } \\
\text { Plan, initiate and } \\
\text { continuously foster the } \\
\text { culture change. }\end{array}$ & HRPBP & $\begin{array}{l}\text { Staff and } \\
\text { Students }\end{array}$ \\
\hline $\begin{array}{l}\text { Insufficient time to achieve } \\
\text { appropriate detail in } \\
\text { modelling; }\end{array}$ & \multirow{2}{*}{$\begin{array}{l}\text { Anticipatable } \\
\text { and } \\
\text { Uncontrollable, } \\
\text { Avoid }\end{array}$} & \multirow{2}{*}{$\begin{array}{l}\text { Effective pre-merger } \\
\text { planning for PMI and } \\
\text { efficient implementation of } \\
\text { PMI Plan. }\end{array}$} & \multirow{2}{*}{$\begin{array}{l}\text { PBSP and } \\
\text { ISPBP }\end{array}$} & \\
\hline $\begin{array}{l}\text { Lack of time and proper } \\
\text { preparation }\end{array}$ & & & & \\
\hline $\begin{array}{l}\text { Partial implementation of } \\
\text { PMI; }\end{array}$ & & $\begin{array}{l}\text { Continuously monitor and } \\
\text { evaluate the PMI }\end{array}$ & & \multirow[b]{2}{*}{$\begin{array}{l}\text { BPBP, HRPBP, } \\
\text { ISPBP and } \\
\text { Management } \\
\text { Staff }\end{array}$} \\
\hline $\begin{array}{l}\text { Re-occurring pre-merger } \\
\text { issues (product / resources } \\
\text { imbalances); Wasting } \\
\text { significant amounts of time } \\
\text { 'putting out fires' ; }\end{array}$ & $\begin{array}{l}\text { Emergent and } \\
\text { Controllable, } \\
\text { Respond }\end{array}$ & $\begin{array}{l}\text { relevant changes at the F } \\
\text { and U levels to ensure } \\
\text { strategic alignment; Support } \\
\text { enhanced communication } \\
\text { and resources sharing across } \\
\text { campuses. }\end{array}$ & $\begin{array}{l}\text { PBSP and } \\
\text { BPBP }\end{array}$ & \\
\hline $\begin{array}{l}\text { Staff perceptions of unequal } \\
\text { standing between campuses; } \\
\text { Different organisational } \\
\text { cultures; Differences in HR } \\
\text { Management approaches } \\
\text { across the campuses }\end{array}$ & $\begin{array}{l}\text { Emergent and } \\
\text { Controllable, } \\
\text { Respond }\end{array}$ & $\begin{array}{l}\text { Prepare staff for future } \\
\text { organisational structure; } \\
\text { Achieve consistent } \\
\text { organisational structure and } \\
\text { HR management practices } \\
\text { across campuses. }\end{array}$ & $\begin{array}{l}\text { HRPBP } \\
\text { with the } \\
\text { support of } \\
\text { BPBP }\end{array}$ & $\begin{array}{l}\text { Management, } \\
\text { Academic and } \\
\text { Administration } \\
\text { Staff }\end{array}$ \\
\hline
\end{tabular}

Table 1 Planned activities for Transformational Preparedness Building 


\subsection{M\&A Preparedness Building Methodology Application}

The previously explained steps of MAPBM can be configured and tailored to plan the detailed activities of needed transformation programs and projects.

In the first step, we identify the entities affected by preparedness building as the management, academic and administration staff, students, services, technical infrastructure and Information Services. In addition, preparedness building requires a strategic program and projects which together could be named Preparedness Building Strategic Program (PBSP), a Business Preparedness Building Project (BPBP) and a HR Preparedness Building Project (HRPBP). The MAIIC model is used to plan the activities for each of these projects and program. Table 1 summarises major activities of the preparedness building transformation mandates for the projects and programs involved.

The second step is to describe the plan of preparedness building transformation by demonstrating the planned interactions of identified entities. Various graphical representations for such descriptions exist; in this case, we have used the so-called 'dynamic business models' based on the Generalised Enterprise Reference Architecture (GERA) Modelling Framework (MF) [28] which is able to integrate multiple aspects in one representation, in the context of life cycle and history. Each 'relationship' in such models is considered a contribution of an entity to another entity's lifecycle activities. For example, Fig. 5 left depicts a relationship (extracted from the models developed for this case study) showing that as a part of its operation, BPBP suggests necessary changes to the structure of Schools A and B (relationship 1) while the Schools' management identifies resulting changes in the architectural and detailed design of products and services offered (relationship 2).

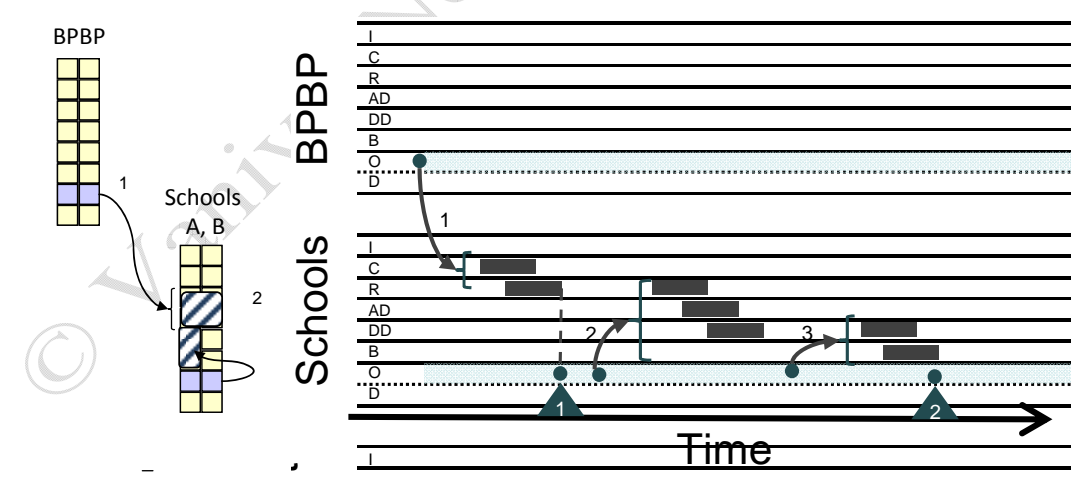

Fig. 5 An example of Dynamic Business Model and Life history Diagram

The third step is to determine the activities and their timing. We use so-called 'life history diagrams' to demonstrate who (an enterprise entity) will do what (detail activity), how (by making changes to one or more lifecycle phases of other entity) and when (relative sequence). Figure 5 shows an extract from the life history models developed for the proposed solution reflecting activities on the time horizon. 


\section{Conclusions and Further Work}

This paper has proposed a Merger and Acquisition Preparedness Building approach featuring identification and categorisation of M\&A issues and a three-step methodology for identifying activities facilitating enterprise-wide transformational preparedness. The approach features EA-specific MF and meta-methodology artefacts in order to achieve an integrated, life cycle-based approach in line with the complexity and 'wickedness' of the problems posed by such endeavours. The paper has also demonstrated the MAPB approach through a case study and has shown what areas could have been addressed by the MAPB components so as to improve the speed, efficiency and facilitate the PMI of the merger project.

The MAPB has the potential to be further evolved into a comprehensive and practical preparedness-building management approach aiming to improve the M\&A success rate by addressing the root causes of issues, so that an enterprise is ready for M\&As and similar enterprise-wide change endeavours. Therefore, a new research project was started in order to develop a checklist of key M\&A issues and their solutions, to define the state of M\&A Preparedness in terms of systemic properties and devise a list of optimal M\&A Preparedness Building Activities.

\section{References}

1. Vaniya, N. and Bernus, P. (2012). Strategic Planning to build Transformational Preparedness: An Application of Enterprise Architecture Practice. ACIS 2012 Proceedings

2. Vaniya, N., Bernus, P. and Noran, P. (2013). Examining Potentials of Building M\&A Preparedness. Proceedings of ICEIS 2013 (in press)

3. Alaranta, M. and Henningsson, S. (2008). An approach to analysing and planning post-merger IS integration: Insights from two field studies. Information Systems Frontiers, 10(3), 307-319,

4. Bannert, V. and Tschirky, H. (2004). Integration planning for technology intensive acquisitions. $R \& D$ Management, 34(5), 481-494.

5. Baro, G. A., Chakrabarti, A. and Deek, F. (2008). Organizational and Informational System Factors in Post-Merger Technology Integration. AMCIS 2008 Proceedings, Paper 359, http://aisel.aisnet.org/amcis2008/359.

6. DiGeorgio, R. (2002). Making mergers and acquisitions work: What we know and don't know Part I. Journal of Change Management, 3(2), 134-148.

7. Eckert, M., Freitag, A., Matthes, F., Roth, S. \& Schilz, C. (2012). Decision support for selecting an application landscape integration strategy in mergers and acquisition. ECIS 2012 Proceedings, Paper 88, http://aisel.aisnet.org/ecis2012/88.

8. Epstein, M. J. (2004). The Drivers of Success in Post-Merger Integration. Organizational Dynamics, 33(2), 174-189.

9. Giacomazzi, F., Panella, C., Pernici, B. and Sansoi, M. (1997). Information Systems integration in mergers and acquisitions: A normative model. Information \& Management, 32, 289-302. 
10. Grainger, N. and McKay, J. (2007). ERP: More than Just a System The Role of ERP in Mergers and Acquisitions. ACIS 2007 Proceedings, Paper 54, http://aisel.aisnet.org/acis2007/54.

11. Hwang, M. (2004). Integrating Enterprise Systems in Mergers and Acquisitions. AMCIS 2004 Proceedings, Paper 12, http://aisel.aisnet.org/amcis2004/12.

12. Jayadev, M. and Sensarma, R. (2007). Mergers in Indian Banking: An Analysis. South Asian Journal of Management, 14 (4), 20-49

13. Kumar, R. (2009). Post-merger corporate performance: an Indian perspective. Management Research News 32(2), 145-157.

14. Larsen, M. H. (2005). ICT Integration in an M\&A Process. PACIS 2005 Proceedings, Paper 95, http://aisel.aisnet.org/pacis2005/95.

15. Lauser, B. (2009). Post-merger integration and change processes from a complexity perspective. Baltic Journal of Management, 5(1), 6-27.

16. Mehta, M. and Hirschheim, R. (2007). Strategic Alignment In Mergers And Acquisitions : Theorizing IS Integration Decision making. Journal of the Association for Information Systems, 8(3), 143-174.

17. Mo, J. P. T., and Nemes, L. 2009. Issues in Using Enterprise Architecture for Mergers and Acquisitions (235-262). In G. Doucet, J. Gotze, P. Saha, \& S. Bernard (Eds.) Coherency Management. AuthorHouse, Bloomington Indiana.

18. Myers, M. D. (2008). Integration of Different ERP Systems: The Case of Mergers and Acquisitions. PACIS 2008 Proceedings, Paper 65, http://aisel.aisnet.org/pacis2008/65.

19. Rodriguez, A. (2008). Mergers and Acquisitions in the Banking Industry: The Human Factor. Organization Development Journal, 26(2), 63-74.

20. Ross, J.W., Weill, P. and Robertson, D.C. (2006). Enterprise architecture as strategy: Creating a foundation for business execution. Haryard Business School Press, Boston, Massachusetts.

21. Robbins, S. S. and Stylianou, A. C. (1999). Post-merger systems integration: the impact on IS capabilities. Information \& Management, 36, 205-212.

22. Schuler, R. and Jackson, S. (2001). HR issues and activities in mergers and acquisitions. European Management Journal, 19(3), 239-253,

23. Stylianou, A. C., Jeffries, C. J. and Robbins, S. S. (1996). Corporate mergers and the problems of IS integration. Information \& Management, 31, 203-213

24. Vernadat, F.B. (2007). Interoperable enterprise systems: Principles, concepts, and methods. Annual Reviews in Control, 31, 137-145

25. Walter, I. (2004). Mergers and acquisitions in banking and finance. Oxford University Press, New York.

26. Wijnhoven, F., Spil, T., Stegwee, R. and Fa, R.T.A. (2006). Post-merger IT integration strategies: An IT alignment perspective. Journal of Strategic Information Systems, 15, 5-28

27. Noran, O. (2008). A Meta-methodology for Collaborative Networked Organisations: Creating Directly Applicable Methods for Enterprise Engineering Projects. VDM Verlag, Saarbrücken.

28. ISO/IEC (2005) ISO/IS 15704:2000/Amd1:2005: Industrial automation systems: Requirements for enterprise-reference architectures and methodologies.

29. Rittel, H. and M. Webber (1973). Dilemmas in a General Theory of Planning. Policy Sciences, 1973. 4: p. 155-169. 